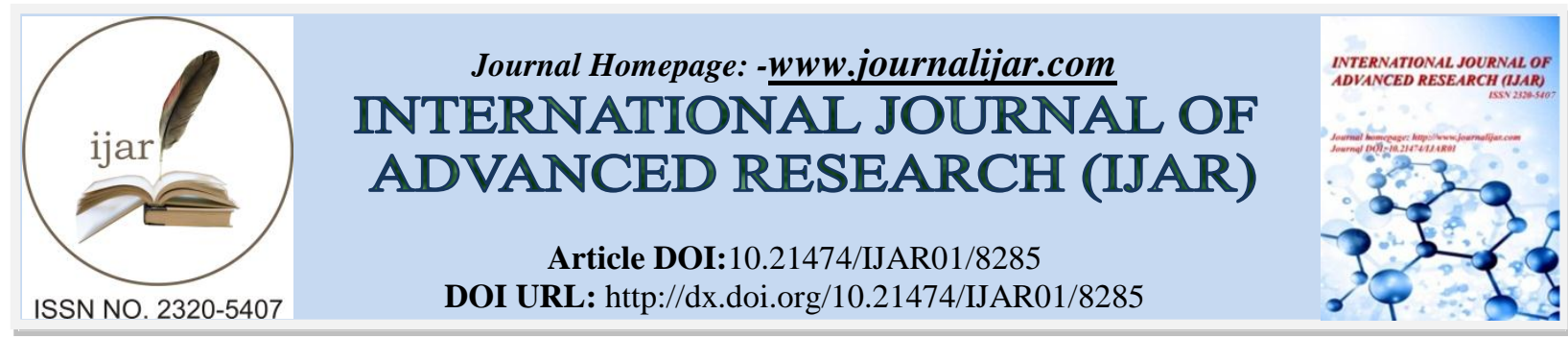

RESEARCH ARTICLE

\title{
PATTERN OF THORACO ABDOMINAL INJURIES IN FATAL ROAD TRAFFIC ACCIDENTS IN PUNE (MAHARASHTRA) INDIA - AN AUTOPSY STUDY.
}

\author{
Rashid Nehal Khan ${ }^{1}$, Ravi Rautji ${ }^{2}$ and K V Radhakrishna ${ }^{2}$. \\ 1. Assistant Professor, Department of Forensic Medicine \& Toxicology, Armed Forces Medical College, Pune \\ 411040 (Mahahrashtra)India. \\ 2. Dept of Forensic Medicine \&Toxicology Armed Forces Medical College, Pune (Mahahrashtra) India.
}

\section{Manuscript Info}

\section{Manuscript History}

Received: 20 October 2018

Final Accepted: 22 November 2018

Published: December 2018

Key words:-

Thoracic Injuries, Abdominal Injuries,

Road Traffic Accident
Abstract

Background:Thoracoabdominal trauma due to road traffic accidents is a leading cause of death in young and productive age group of society. Road Traffic Accident (RTA) is defined as accident which takes place on the road between two or more objects, one of which must be any kind of a moving vehicle.The incidence of these injuries is increasing with the increase in the use of motor vehicles. The World Health Organization stated in its report that deaths due to Road Traffic Accidents are the ninth leading cause of death worldwide. Among non communicable conditions it is the sixth leading cause of death. The Thoracoabdominal region involves the largest surface area of the body and encloses vital organs like heart, lungs, great blood vessels, liver, spleen and kidneys. The paper brings forward the pattern of thoracoabdominal injuries encountered in RTAs and the demographic factors associated with it.

Aims and Objectives:To study the anatomical pattern of thoracic and abdominal injuries in fatal road traffic accidents and its relationship to various demographic factors.

Results:-The study was done to study the pattern of thoracoabdominal injuries in road traffic accident fatalities in Pune district of Maharashtra. The study was done for period of 18 months involving 120 cases. All the 120 autopsy cases involved in research were studied in patterns of injuries namely abrasions, contusions, lacerations, fractures and ruptures involving the skin of thorax and abdomen, bones involving abdomen and thorax and the organs involving the thoracoabdominal cavity. The total number of injuries in thorax(n $=227)$ and abdomen $(n=213)$ were noted as to the organs involved and to the nature of injuries. With data analysis a study was done as to ascertain the percentage of different body parts sustaining injuries and nature of injuries sustained. Amongst the organs in thoracic cavity, lung was the most commonly injured organ (35.24\%).60\% lung injuries were contusions and $40 \%$ were lacerations.However the commonest injury of thorax was rib fracture (36.56\%).In abdomen commonest solid organ involved was liver $(31.45 \%)$.

Corresponding Author:-Rashid Nehal Khan.

Address:-Assistant Professor, Department of Forensic Medicine \& Toxicology, Armed Forces Medical College, Pune 411040 (Mahahrashtra)India. 
Conclusion:It may be said that RTAs with thoracoabdominal visceral injuries constitute a potential threat to life if not managed with multidisciplinary approach.

Copy Right, IJAR, 2017,. All rights reserved.

\section{Introduction:-}

Accidents, tragically, are not often due to ignorance, but are due to carelessness, thoughtlessness and over confidence. Human, vehicle and environmental factors play roles before, during and after an accident. Accidents, therefore, can be studied in terms of agent, host and environmental factors and epidemiologically classified into time, place and person distribution. ${ }^{1}$ Accidents constitute a veritable epidemic. They rank third in order among the leading causes of death while fatalities due to road traffic accidents are the ninth leading cause of death and are steadily rising. ${ }^{2}$ Road traffic accidents account for 10.1 percent of total accidental deaths in India, which is the highest among accidental deaths. Amongst the deaths due to accidents caused by human interference (i.e. excluding those caused by natural calamities), road traffic accidents account for 3.6 percent of deaths, which is the highest in the category. Major contributors to the total 1,14,590 deaths due to road traffic accidents in India, were the states of Andhra Pradesh (13,772), Maharashtra (12,616), Uttar Pradesh $(12,555)$ and Tamil Nadu $(12,036) .^{3}$

\section{Material AndMethods:-}

Medico-legal cases of fatal Road Traffic Accident victims showing Thoraco-abdominal Injuries carried out at the mortuary of tertiary care hospital were selected for the study. A total of 120 medico-legal autopsies were studied and relevant data was collected. For the purpose of the study, a Road Traffic Accident (RTA) was defined as accident which took place on the road between two or more objects, one of which must be any kind of a moving vehicle

\section{Criteria For Selection Of Cases:- Inclusion Criteria:-}

All the medico legal autopsies showing thoracic and abdominal injuries who have definite history of road traffic accidents were included in the study.

Autopsies showing multiple injuries along with thoracic and abdominal injuries due to road traffic accidents were also included in the study.

\section{Exclusion Criteria:-}

Decomposed bodies in which organs had liquefied were excluded.

\section{Collection Of Data:-}

All the relevant findings observed during the autopsy were recorded in a proforma and data analysed

\section{Observations:-}

Thoracic injuries -Organs involved:-

Amongst a total of 227 cases with thoracic injuries, rib fractures were noted in maximum number of cases $(n=83$, $36.56 \%$ ). In 39 cases fracture of right ribs was seen, 12 cases showed fracture of left ribs and 32 cases had bilateral rib fractures. Lung injuries were second in number $(n=80,35.24 \%))$. In 27 cases contusion of right lung was seen and 21 cases had contusion of left lung. Laceration of right lung was seen in 23 cases and laceration of left lung was seen in 9 cases. Amongst visceral injuries, lung contusion was most common $(n=48,21.14 \%)$. Other injuries in thoracic cavity were rupture of diaphragm ( 8 cases), contusion / laceration of heart ( 7 cases), rupture of aorta (6 cases), fracture sternum (6 cases), rupture of great vessels (3 cases) and fracture clavicle (1 case)(Table 1 )

\footnotetext{
Abdominal injuries - Organs involved:-

Amongst a total of 213 abdominal injuries, liver injuries was the most common and were found in 67 cases (28.63 $\%)$. Contusion was seen in 10 cases and laceration of liver was found in 57 cases. Second most common abdominal organ to be injured was kidney $(n=45,19.23 \%)$. Contusion of right kidney was seen in 18 cases and contusion of left kidney in 10 cases. Laceration of right kidney was seen in 13 cases and that of left kidney in 4 cases. Spleen was next most common organ to get injured $(n=24,10.25 \%)$. Contusion of spleen was seen in 5 cases and laceration in 19 cases. Other injuries to abdominal organs were rupture / contusion/ laceration of small intestine (9 cases), injury
} 
to large intestine (2 cases), contusion of mesentery (16 cases), rupture of bladder (11 cases) and rupture of ureter (1 case). 4 cases showed retro-peritoneal haematoma. Abrasions and contusions of abdominal wall were seen in 31 cases. Pelvic fracture was seen in 21 cases. (Table 2)

Table 1:-Thoracic Injury - Organs Involved

\begin{tabular}{|l|l|l|}
\hline Anatomical Organ & Number of Injuries & Percentage (Out of 227 ) \\
\hline Chest wall & 33 & $14.53 \%$ \\
\hline Clavicle & 01 & $0.44 \%$ \\
\hline Sternum & 06 & $2.64 \%$ \\
\hline Rib & 83 & $36.56 \%$ \\
\hline Lung & 80 & $35.24 \%$ \\
\hline Heart & 07 & $3.08 \%$ \\
\hline Aorta & 06 & $2.64 \%$ \\
\hline Great Vessels & 03 & $1.32 \%$ \\
\hline Diaphragm & 08 & $3.52 \%$ \\
\hline Total & 227 & $100 \%$ \\
\hline
\end{tabular}

Table 2: Abdominal Injury - Organs Involved

\begin{tabular}{|l|l|l|}
\hline Anatomical Organ injured & Number of Injuries & Percentage ( Out of 213) \\
\hline Abdominal wall & 31 & $14.55 \%$ \\
\hline Liver & 67 & $31.45 \%$ \\
\hline Spleen & 24 & $11.27 \%$ \\
\hline Kidney & 45 & $21.13 \%$ \\
\hline Stomach & 03 & $1.41 \%$ \\
\hline Small Intestine & 09 & $4.22 \%$ \\
\hline Large Intestine & 02 & $0.93 \%$ \\
\hline Mesentery & 16 & $7.51 \%$ \\
\hline Urinary Bladder & 11 & $5.16 \%$ \\
\hline Ureter & 01 & $0.46 \%$ \\
\hline RetroPeritonealHaematoma & 04 & $1.88 \%$ \\
\hline Total & 213 & $100 \%$ \\
\hline
\end{tabular}

\section{Age wise incidence:-}

Age wise distribution of cases was found to be different for the two sexes. It shows that male victims from age group $20-29$ years are maximum $(n=37,36.63 \%)$ as compared to the rest of age group among male population. The age group $30-39$ years ranks second with $(n=21,20.79 \%)$ followed by $10-19$ years group $(n=11,10.89 \%)$ and $40-49$ years group $(n=10,9.9 \%)$ as third and fourth respectively. Rest of the age groups are 60-69 years $(n=$ $6,5.94 \%), 70$ years and above $(n=4,3.96 \%), 50-59$ years group $(n=3,2.97 \%)$ and $0-9$ years group $(n=2$, $1.98 \%)$

In comparison to male victims, the female victims show different age wise distribution with maximum fatalities in age group $30-39$ years group $(n=6,31.57 \%$ ). The age group $40-49$ years group and $60-69$ years group are second $(n=4,21.05 \%) .10-19$ years group is third $(n=2,10.52 \%)$ The age group $20-29$ years and $0-9$ years are fourth $(\mathrm{n}=1,5.26 \%)$.

The above observations establish that both sexes taken together, theage group of $20-49$ years is most vulnerable to fatalities in road traffic accidents. $(n=65,54.16 \%)$.

\section{Sex wise distribution of cases:-}

The observationsshow that in fatal road traffic accidents studied the number of male victims $(\mathrm{n}=101,84.17 \%)$ was much more than females $(\mathrm{n}=19,15.83 \%)$, establishing that male population is at a much higher risk as compared to females. 


\section{Time interval between injury and hospitalization:-}

Majority of injured victims availed medical treatment within $0-1 \mathrm{hrs}(\mathrm{n}=60,50 \%)$ while $29(16 \%)$ availed treatment within $1-12$ hrs post injury. The incidence of spot deaths were $(n=23,19.16 \%)$. The data regarding time interval of hospitalization of two cases was unknown.

\section{Mode of transfer of casualties:-}

Most common mode of transfer of casualties was by Taxis $(\mathrm{n}=55,45.83 \%)$ followed by Ambulances $(\mathrm{n}=20,16$. $67 \%)$, Cars $(\mathrm{n}=19,15.83 \%)$, Auto Rickshaws $(\mathrm{n}=15,12.5 \%)$ and Police Vehicle $(\mathrm{n}=9,7.5 \%)$. Two casualties were evacuated in unknown vehicles.

\section{Discussion:-}

\section{Thoracic \& Abdominal Injuries-Organs involved:-}

In the present study (Table 1) amongst a total of 227 thoracic injuries, rib fractures were noted in maximum number of cases $(n=83,36.56 \%)$. Lung injuries were a close second in number $(n=80,35.24 \%)$ ). As regards type of injury, lung contusion was most common $(\mathrm{n}=48,21.14 \%)$. Lung laceration was next in line $(\mathrm{n}=32,14.1 \%)$. Other injuries pertaining to thoracic cavity were rupture of diaphragm (8 cases), Contusion / Laceration of heart (7 cases), rupture of aorta ( 6 cases), fracture sternum ( 6 cases), rupture of great vessels ( 3 cases) and fracture clavicle ( 1 case).

In the present study (Table 2) among the total of 213 abdominal injuries, blunt injuries to liver were the most common and were found in 67 cases $(28.63 \%)$. Contusion of liver was seen in 10 cases and laceration of the organ in 57 cases. Second most common abdominal organ to be injured was kidney $(\mathrm{n}=45,19.23 \%)$. Spleen was the next most common organ to get injured $(\mathrm{n}=24,10.25 \%)$. Among injury to other abdominal organs, rupture / contusion/ laceration of small intestine were seen in 9 cases, injury to large intestine in 2 cases, contusion of mesentery in 16 cases, rupture of bladder in 11 cases and rupture of ureter in 1 case. 4 cases showed retro peritoneal haematoma.

According to Bowley D and Boffard $\mathrm{K}^{4}$ thoracic injury directly accounts for $20-25 \%$ of deaths due to trauma; thoracic injury or its complications are a contributing factor in a further $25 \%$ of trauma deaths. Aortic injuries contribute to $15 \%$ of RTA fatalities. The reported incidence of diaphragmatic rupture is between $0.8 \%$ and $1.6 \%$ in patients admitted to hospital with blunt trauma. The most commonly injured intra abdominal organ following blunt trauma is the spleen. In their study, the reported incidence of bowel and mesenteric injuries after blunt abdominal trauma was approximately $1.3 \%$. A study byKumar $\mathrm{A}_{\text {et }} \mathrm{al}^{5}$ says that most commonly injured abdominal organ is liver $(n=532,21.52 \%)$. Singh $\mathrm{H}$ and Dhattarwal ${ }^{6,7}$ report chest injuries in $44 \%$ cases which included fracture of ribs in $36.9 \%$ cases, contusions and lacerations of lungs in $29.8 \%$ cases and rupture of diaphragm in $2 \%$ cases. Abdominal injuries were seen in $31.8 \%$ cases and included lacerations of liver (26.9\%), spleen (12.7\%), gut (4.7\%), kidneys $(3.8 \%)$ and bladder $(2.9 \%)$.Newman $\mathrm{R}$ et $\mathrm{al}^{8}$ report that in frontal impacts in unrestrained occupants, rib fracture was the most common injury followed by lung injury.Sevit $S^{9}$ reports fracture multiple ribs was most common (49.8\%) of chest injuries while laceration of liver was the most common abdominal organ injured $(62.1 \%$ of abdominal injuries.) Findings of the present study in this respect tally with those of the above mentioned studies, except for the study by Bowley D and Boffard $\mathrm{K}^{4}$ which reports spleen as the most commonly injured abdominal organ.

\section{Age wise incidence:-}

The present study shows that male victims from age group $20-29$ years are maximum in number $(\mathrm{n}=37,36.63 \%)$ as compared to other age groups amongst males. In comparison to male victims, the female victims show a different trend with maximum fatalities in age group $30-39$ years group $(n=6,31.57 \%)$. The above observation clearly shows that both sexes taken together, age group $20-49$ years is most vulnerable to fatalities in road traffic accidents. $(\mathrm{n}=65,54.16 \%)$ and extremes of life the least $(5.88 \%)$.

NCRB data of $2007,{ }^{3}$ also has recorded the age group maximally involved as $25-35 \mathrm{yr}(18.3 \%)$. Kaul A et al ${ }^{10}$ report that the principal age group involved in fatal RTA was 25-44 years, $(33.68 \%)$ and least involved were extremes of ages i.e. below 10 years, $5.38 \%$, and above 65 years. Meera $\mathrm{T}$ and Nabachandra $\mathrm{H}^{11}$ report the commonest age group of the victims as 21-30 years $(20.80 \%)$. Jha $\mathrm{N}$ and Agarwal C S ${ }^{12}$ report that $58 \%$ of the injuries occurred in the 15-44 year group. Kumar A et $\mathrm{al}^{5}$ report that the commonest age group affected was between 21-40 years involving $1341(54.24 \%)$ cases. Thus the findings of the present study, regarding the most common age of victims involved in fatal road traffic accidents are consistent with the above studies. 


\section{Sex wise distribution of cases:-}

In the present study it is seen that majority of deceased were males $(84.16 \%)$ and females were $(15.84 \%)$ The Male: Female ratio was 5.65: 1 . Similar results have been reported by Jha $\mathrm{N}$ et al ${ }^{1}$ who reported that there were $83 \%$ male and $17 \%$ female accident victims. Singh Y N et al ${ }^{13}$ state that a total of 1628 male and 244 females were killed in road traffic accidents giving a male : female ratio of 7:1. Singh $\mathrm{H}$ and Dhattarwal $\mathrm{S} \mathrm{K}^{6}$ report that males outnumbered females in a ratio of 9:1. Meera $\mathrm{T}$ and Nabachandra $\mathrm{H}^{11}$ have stated that males outnumbered females in a ratio of 3.8:1. Present study is consistent with above studies. The reason attributed is that it is the male who commonly goes out to work and thus is more vulnerable to road traffic accidents.

\section{Time interval between injury and hospitalization:-}

In the present study it was seen that majority of injured victims availed medical treatment within $0-1 \mathrm{hrs}(\mathrm{n}=60$, $50 \%)$ while $(\mathrm{n}=35,29.16 \%)$ availed treatment within $1-12 \mathrm{hrs}$ post injury. The incidence of spot deaths was $(\mathrm{n}=$ $23,19.16 \%)$. The data regarding time interval of hospitalization of two cases was not known. This reveals that almost $50 \%$ of the casualties could not be transferred to hospital within the first 'Golden' hour which might have saved precious lives. Another study which has studied time taken for transfer of casualties to the hospital is by Singh $\mathrm{H}$ and Dhattarwal SK ${ }^{6}$, which reports that $15.4 \%$ died on the spot, $4.2 \%$ cases reached hospital within first 15 minutes, $24 \%$ reached within half an hour and $57 \%$ reached in next one hour and remaining $19 \%$ were rushed to hospital after more than one and half hours. No one received any treatment or first aid at the site of accident. Lowe D K et al ${ }^{14}$ have reported that 143 cases $(51.4 \%)$ were dead at the spot or in transit despite emergency resuscitation measures. 45 cases $(16.2 \%)$ died within $01 \mathrm{hr}$ and 27 cases $(9.7 \%)$ died after $01 \mathrm{hr}$ without ICU admission. Only 63 cases $\left(22.7 \%\right.$ ) could avail ICU treatment. Teanby D N et al ${ }^{15}$ report that among 75 severely injured children (ISS $>15$ or death), $38(50 \%)$ died at spot and $15(20 \%)$ deaths occurred before admission to hospital. SinghY N et $\mathrm{al}^{13}$ report that hospital death was the most common outcome (1027, $54.86 \%$ cases), followed by spot deaths (561, $29.96 \%)$ and death on the way to hospital $(284,17.17 \%)$. Overall, $50 \%$ of casualties died before reaching the hospital. Findings of all the above studies, including the present one, reveal that almost $50 \%$ of victims died due to delay in hospitalization beyond the 'Golden Hour'. This highlights the necessity of establishing Regional Trauma Care System, facilitating early hospitalization of RTA victims. Shapiro M B et al ${ }^{16}$ in "Damage Control: Collective Review" have suggested a three part damage control method to save the life of trauma victims. With the above approach, a $50 \%$ decrease in mortality and $60 \%$ decrease in morbidity was noticed.

\section{Mode of transfer of casualties:-}

In the present stud it is observed that most common mode of transfer of casualties was Taxis $(n=55,45.83 \%)$ and Ambulances evacuated only $19(16.67 \%)$ casualties. Thus highlighting the lack of proper facilities for evacuation of trauma victims. Ambulances can start emergency resuscitation in transit and thus can save many lives. Similar findings are reported from Indian Council of Medical Research in its annual report 2007- 2008 ${ }^{17}$, whichstates that most of the injured were taken to the hospital in private vehicles and taxis and ambulance was used in only $19 \%$ cases. Thus the findings of the present study are consistent with the ICMR annual report.

\section{Conclusions:-}

Urgent attention needs to be paid to the prevention and control of road accidents. Until recently, it was believed, that a vast majority of accidents, are the result of, 'human error.' Professionals however have now opined that it is not so easy to pinpoint these 'errors' to an individual or an organization. We have to do away with the tradition of fixing blame and educate the society about road safety..

\section{References:-}

1. Jha $\mathrm{N}$ et al .Epidemiological study of Road Traffic Accidents cases: A study from South India. Indian Journal of Community Medicine. Jan.-Mar., 2004; 29(1).

2. WHO Global Burden of Disease 2004; Part 1:11.

3. Accidental Deaths in India. Incidence and Rate of Accidental Deaths during the Decade. NCRB, Ministry of Home Affairs, Govt. of India, New Delhi

4. Bowley D, Boffard K . Pattern of injury in motor vehicle accidents. World Wide Wounds. Oct 2002.

5. Kumar A et al. Fatal road traffic accidents and their relationship with head injuries: An epidemiological survey of five years. Indian Journal of Nuerotrauma. 2008; 5(2):63-67.

6. Singh H, .Dhattarwal S K. Pattern and Distribution of Injuries in Fatal Road Traffic injuries in Rohtak (Haryana). Journal of Indian Association of Forensic Medicine. 2004; 26 (1)971 -73. 
7. Singh $\mathrm{H}$ et al. A Review of Pedestrian Traffic Fatalities. Journal of Indian Association of Forensic Medicine. 2007,29(4):971-73

8. Newman R J, Jones I S. A prospective study of 413 Consecutive Car Occupants with Chest injuries.Journal of Trauma. Feb 1984; 24 (2):129 - 135.

9. Sevitt S. Fatal Road Accidents Injuries, complications and Causes of Deaths in 250 Subjects. British Journal of Surgery. July 1968; 55(7): 481- 505.

10. Kaul A et al. An Epidemiogical Study of Fatal Road Traffic Accidents in Allahabad Region.. Indian Journal of Forensic Medicine and Toxicology. 2005; 3(1).

11. Meera T., Nabachandra H. A Study of Pattern and Injury Severity Score in Blunt Thoraco-abdominal Trauma cases in Manipal.Medico-Legal Update. April-June. 2005, Vol.5, No.2 :47-52.

12. Jha N, Agarwal C S. Epidemiological Study of Road Traffic Accident Cases: A Study from Eastern Nepal. Regional Health Forum WHO South East Asia Region. 2004;8 (1).

13. Singh Y N et al. An Epidemiological Study of Road Traffic Accident Victims in Medico legal Autopsies .Journal of Indian Association of Forensic Medicine. 2005; 27; 971-73.

14. Lowe D K et al. Patterns of Death, Complication and Error in the Management of Motor Vehicle Accident Victims : Implications for a Regional System of Trauma Care . Journal of Trauma; June 1983; 23(6): 503 -09.

15. Teanby D N et al. Regional review of Blunt Trauma in Children. British Journal of Surgery. 1994; 81: 53 -55.

16. Shapiro M B et al. Damage Control Collective Review. Journal of Trauma and Acute Care Surgery:Nov2000;49(5): :969-78.

17. ICMR Annual Report 2007 -08: 67-68. 